\title{
PENGARUH PELAYANAN PRIMA TERHADAP KEPUASAN NASABAH PADA PT. BPR. SURYA KATIALO
}

\author{
SUBAGIYO, ZURAEDAH INDAH \\ subagiyo7141@gmail.com, zurinindi@gmail.com
}

\begin{abstract}
The development of the banking world today is moving very fast accompanied by increasingly broad and complex challenges. This makes banks have to be fast and responsive in carrying out their functions and responsibilities to serve the community. Bank is one of the financial institutions engaged in financial services, so it must be able to provide the best service (service excellent) in order to win the competition which is increasingly competitive. Furthermore, the problems formulated how the implementation of excellent service, the level of customer satisfaction and how much influence the excellent service has on customer satisfaction at PT. BPR. Surya Katialo. The goal is to find out how the implementation of excellent service, the level of customer satisfaction and the relationship between excellent service and customer satisfaction. The research method used is descriptive analysis. Researching the population and determining the survey on the object of the company's research. The study population was 300 people with saturated sampling so that the number of samples in this study amounted to 30 people. The results showed that the correlation between excellent service and customer satisfaction resulted $r=0.86$ including the very strong category and the results of statistical testing through the t test (at an error rate of 5\% t table value 2.048) while the results of the analysis obtained tcount 8.94 it was stated that there were significant effect of excellent service on increasing customer satisfaction. The coefficient of determination is $73.96 \%$ so that customer satisfaction is influenced by excellent service by $73.96 \%$. As for linear regression, the equation $Y=9.98+1.56 X$ means that if the value of $X$ is increased by 1 unit, the value of $Y$ will increase by 1.56 at a constant of 9.98. The conclusion of this study is that there is a positive and significant effect of excellent service on customer satisfaction at PT. BPR. Surya Katialo. Suggestions to increase customer satisfaction PT. BPR. Surya Katialo in order to improve excellent service so that in the end the increase in customer satisfaction will be much more leverage.
\end{abstract}

Keywords: Excellent Service And Satisfaction.

Abstrak: Perkembangan dunia perbankan yang dewasa ini bergerak sangat cepat disertai dengan adanya tantangan-tantangan yang semakin luas dan kompleks. Hal tersebut membuat perbankan harus cepat dan tanggap dalam menjalankan fungsi dan tanggung jawabnya melayani masyarakat. Bank adalah salah satu lembaga keuangan yang bergerak dalam bidang pelayanan jasa keuangan, sehingga harus dapat memberikan pelayanan yang terbaik (service excellent) agar dapat memenangkan persaingan yang semakin hari semakin kompetitif. Selanjutnya dirumuskan permasalahan bagaimana pelaksanaan pelayanan prima, tingkat kepuasan nasabah dan seberapa besar pengaruh pelayanan prima terhadap kepuasan nasabah pada PT. BPR. Surya Katialo. Tujuannya untuk mengetahui bagaimana pelaksanaan pelayanan prima, tingkat kepuasan nasabah dan hubungan pelayanan prima dengan kepuasan nasabah. Metode penelitian yang digunakan adalah deskriptif analis. Meneliti populasi dan menentukan survei pada objek penelitian perusahaan. Populasi penelitian sebanyak 300 orang dengan pengambilan sampel secara sampling jenuh sehingga jumlah sampel pada penelitian ini berjumlah 30 orang. Hasil penelitian menunjukan bahwa korelasi 
antara pelayanan prima dengan kepuasan nasabah dihasilkan $r=0,86$ termasuk kategori sangat kuat dan hasil pengujian statistik melalui uji t (pada tingkat kekeliruan $5 \%$ nilai $t_{\text {tabel }} 2,048$ ) sedangkan hasil analisis diperoleh $t_{\text {hitung }} 8,94$ maka dinyatakan bahwa terdapat pengaruh signifikan pelayanan prima terhadap peningkatan kepuasan nasabah. Koefisien determinasi 73,96\% sehingga kepuasan nasabah dipengaruhi oleh pelayanan prima sebesar $73,96 \%$. Sedangkan untuk regresi linear dihasilkan persamaan $\mathrm{Y}=9,98+1,56 \mathrm{X}$ yang artinya apabila nilai $\mathrm{X}$ dinaikkan 1 satuan maka nilai $\mathrm{Y}$ akan naik sebesar 1,56 pada konstanta 9,98. Kesimpulan dari penelitian ini terdapat pengaruh positif dan signifikan pelayanan prima terhadap kepuasan nasabah pada PT. BPR. Surya Katialo. Saran untuk meningkatkan kepuasan nasabah PT. BPR. Surya Katialo agar meningkatkan pelayanan prima sehingga pada akhirnya peningkatan kepuasan nasabah akan jauh lebih maksimal.

Kata Kunci: Pelayanan Prima Dan Kepuasan.

\section{A. Latar Belakang Masalah}

Persaingan yang ketat antar bank dewasa ini mendorong setiap bank untuk memberikan layanan terbaik kepada nasabahnya. Masing-masing bank mempunyai program yang terus diperbarui. Semua itu dimaksudkan untuk sebanyak mungkin menarik masyarakat untuk menjadi nasabah baru, serta untuk mempertahankan supaya nasabah lama tidak beralih ke bank lain. Demikian pula halnya dengan nasabah, mereka telah menjadi pandai memilah-milah produk yang mana memberikan keuntungan yang lebih, serta pelayanan yang memuaskan. Sebagian perusahaan sengaja memanjakan nasabah melalui pelayanan yang diberikan bahkan dewasa ini nasabah sudah dianggap sebagai raja dan nasabah juga dianggap sebagai bagian dari perusahaan yang harus segera dipenuhi kebutuhan serta keinginannya seperti dilayani secara cepat dan akurat. Untuk menghadapi persaingan antara lembaga perbankan yang semakin ketat, sekarang ini telah dikembangkan berbagai konsep pelayanan nasabah dengan tujuan untuk mempertahankan nasabah dan menjangkau nasabah-nasabah potensial.

PT. BPR. Surya Katialo adalah bank perkreditan rakyat milik masyarakat nagari Sulit Air Solok yang memiliki jaringan usaha di daerah solok sekitarnya. Akan tetapi dalam survei yang dilakukan di lapangan ada hubungan antara pegawai dan nasabah yang kurang baik. Hal ini tercermin dalam komunikasi antara pegawai dan nasabah masih kurang, kemampuan melayani dan sikap pegawai dengan nasabah masih kurang sehingga berdampak pada pelayanan yang masih kurang pula yang mengakibatkan adanya keluhan-keluhan dari nasabah yang kurang puas terhadap pegawai. Oleh karena itulah dalam menunjang peningkatan nasabah, maka perlunya dilakukan penilaian mengenai pelaksanaan dimensi pelayanan prima dan pengaruhnya terhadap peningkatan jumlah nasabah. Selanjutnya dalam penelitian ini yang menjadi titik pokok penelitian adalah nasabah penabung, khususnya Tabungan Pasar. Perkembangan nasabah penabung, khususnya tabungan pasar, mengalami peningkatan untuk setiap tahunnya. Dengan adanya peningkatan tersebut maka perlu dilakukan penilaian mengenai pelaksanaan pelayanan prima yang telah dilakukan. Hal ini dimaksudkan untuk dapat mengetahui pengaruh pelayanan prima yang dilakukan oleh PT. BPR. Surya Katialo terhadap kepuasan nasabah.

Berdasarkan identifikasi masalah yang terungkap pada PT. BPR. SURYA KATIALO. Untuk kepentingan penelitian, selanjutnya penulis mengambil / menetapkan 2 [dua] variabel yang akan diteliti yaitu: 1) Variabel X : Pelayanan prima; 2) Variabel $Y$ : Kepuasan nasabah. Berdasarkan latar belakang yang telah 
dikemukakan di atas, maka penulis mengidentifikasikan beberapa masalah sebagai berikut: 1) Bagaimana pelaksanaan pelayanan prima yang dilakukan oleh PT. BPR. Surya Katialo? 2) Bagaimana tingkat kepuasan nasabah yang ada pada PT. BPR. Surya Katialo? dan 3) Seberapa besar pengaruh pelayanan prima terhadap kepuasan nasabah pada PT. BPR. Surya Katialo?

\section{B. Metodologi Penelitian}

Metode penelitian yang digunakan untuk mengetahui pengaruh antar variabel $\mathrm{X}$ (pelayanan prima) dengan variabel $\mathrm{Y}$ (kepuasan nasabah) adalah metode deskriptif analis, dimana metode ini menurut Sugiyono (2004:11) bahwa : "Metode deskriptif analis adalah penelitian yang digunakan untuk mengetahui nilai variabel mandiri, baik satu variabel dependent atau lebih tanpa membuat perbandingan atau menghubungkan dengan variabel yang lain". Menurut Arikunto (2006 : 130) populasi adalah keseluruhan objek penelitian Populasi yang dimaksud dalam penelitian ini adalah nasabah tabungan pasar pada PT. BPR. SURYA KATIALO yang melakukan transaksi pada bulan maret s.d. mei 2019. Jumlah populasinya adalah 300 nasabah. Menurut Arikunto apabila subyeknya kurang dari 100, lebih baik diambil semua, sehingga penelitiannya merupakan penelitian populasi. Selanjutnya jika subjeknya lebih besar dari 100 dapat diambil antara 10\% - 15\% atau 20\% - 25\% atau lebih. Dalam penelitian ini penulis hanya mengambil sampel sebesar $10 \%$. Untuk menentukan besarnya sempel digunakan rumus Arikunto, Suharsimi ( 2006 : 130) yaitu :

$$
\begin{aligned}
\mathrm{n} & =\text { jumlah nasabah } \times 10 \% \\
& =300 \times 10 \%=30
\end{aligned}
$$

Jadi, sampel yang akan diambil adalah 30 responden dari 300 nasabah.

Dalam penelitian ini jenis data yang digunakan adalah data primer, yaitu data yang diperoleh dari sumber asli tanpa perantara. Dalam hal ini penulis menggunakan observasi sebagai data primer untuk digunakan sebagai data penelitian. Teknik pengolahan data yang digunakan oleh penulisan setelah data yang digunakan terkumpul adalah dengan metode kualitatif dan metode kuantitatif. Dan data-data yang terkumpul itu selalu disajikan dalam bentuk tabel dan grafik. Metode kualitatif, yaitu metode pengolahan data yang didasarkan pada metode keadaan perusahaan yang menjadi objektif penelitian ini, yang dianalisis dengan menggunakan fakta-fakta. Metode kuantitatif, yaitu metode yang menjelaskan besarnya pengaruh dan hubungan yang dinyatakan dengan angka-angka berdasarkan hasil perhitungan dan dianalisa dengan menggunakan rumus-rumus statistik.

\section{Hasil dan Pembahasan}

\section{Besarnya Pengaruh Pelayanan Prima terhadap Kepuasan Nasabah}

Untuk mengetahui apakah terdapat hubungan antara pelayanan prima dengan kepuasan nasabah

$$
\begin{aligned}
& r_{y,}=\frac{n\left(\sum X Y\right)-\left(\sum X\right)\left(\sum Y\right)}{\sqrt{\left(n \sum X^{2}-\left(\sum X\right)^{2}\right)\left(n \sum Y^{2}-\left(\sum Y\right)^{2}\right)}} \\
& r_{x y}=\frac{30(54.417)-(925)(1.744)}{\sqrt{\left(30 \times 28.933-(925)^{2}\right)\left(30 \times 102.744-(1.744)^{2}\right)}} \\
& r_{x y}=\frac{1.632 .510-1.613 .200}{\sqrt{(867.990-855.625)(3.082 .320-3.041 .536)}} \\
& r_{x y}=\frac{19.310}{\sqrt{(12.365)(40.784)}} r_{x y}=\frac{19.310}{22.456}=0,86
\end{aligned}
$$


Berdasarkan dari hasil perhitungan data tabel di atas, diperoleh nilai koefisien korelasi (r) hitung sebesar 0,86. Harga (r) hitung tersebut apabila di interprestasikan pada skala perhitungan menurut Sugiyono (2008 : 250) adalah sangat kuat.

\section{Daftar Interval Koefisien dan Tingkat Hubungan}

\begin{tabular}{|c|c|}
\hline Interal Kodisien & Tingkat Hubungan \\
\hline $0,000-0,199$ & Sangat Rendah \\
\hline $0,200-0,399$ & Rendah \\
\hline $0,400-0,599$ & Sedang \\
\hline $0,600-0,799$ & Kuat \\
\hline $0,800-1,000$ & Sangat Kuat \\
\hline
\end{tabular}

\section{Koefisien Determinasi $\left(\mathbf{r}^{2}\right)$}

Langkah yang dilakukan untuk mengetahui koefisien determinasi menggunakan rumus:

$\mathrm{KD}=\mathrm{r}^{2} \times 100 \%$

Sehingga diperoleh :

$\mathrm{KD}=(0,86)^{2} \times 100 \%$

$=0,7396 \times 100 \%=73,96 \%$

Dari langkah-langkah perhitungan di atas dapat diartikan bahwa pengaruh pelayanan prima terhadap kepuasan nasabah sebesar 73,96\%, ini menunjukkan adanya pengaruh yang kuat yang ditimbulkan dari pelayanan prima untuk meningkatkan kepuasan nasabah. Sedangkan faktor lain yang mempengaruhi kepuasan nasabah adalah sebesar $100 \%-73,96 \%=26,04 \%$.

\section{Uji Signifikasi (uji t)}

Uji signifikasi digunakan untuk mengetahui apakah hipotesis yang diajukan diterima atau ditolak. Dalam hal ini penulis membandingan antar nilai $t_{\text {hitung }}$ dengan $t_{\text {tabel }}$

$$
t=\frac{0,86 \sqrt{30-2}}{\sqrt{1-(0,86)^{2}}}=\frac{0,86 \sqrt{28}}{\sqrt{1-0.74}}=\frac{0,86 \times 5,3}{\sqrt{0,26}}-\frac{4,56}{0,51}=8,94
$$

Berdasarkan hasil perhitungan uji $\mathrm{t}$ di atas diperoleh $\mathrm{t}_{\text {hitung }}$ sebesar 8,94. Harga $t_{\text {hitung }}$ tersebut selanjutnya dibandingkan dengan nilai tabel untuk uji dua pihak dengan taraf signifikasi $(\alpha)$ sebesar $5 \%$ dan $\mathrm{dk}=30$-2, maka diperoleh nilai $\mathrm{t}_{\text {tabel }}$ sebesar 2,052. Jadi $t_{\text {hitung }}>t_{\text {tabel }}$ maka hipotesis diterima sehingga dapat disimpulkan bahwa terdapat pengaruh signifikan pelayanan prima terhadap peningkatan kepuasan nasabah pada PT. BPR Surya Katialo. Dengan demikian hipotesis terbukti.

\section{Regresi Linear}

Analisis regresi bertujuan untuk memprediksi besarnya perubahan yang terjadi pada variabel kepuasan nasabah jika nilai variabel pelayanan prima diubah.

Persamaan umum regresi linear adalah :

Diketahui :

$$
y=a+b x
$$

$$
\begin{array}{ll}
\mathrm{n}=30 & \Sigma \mathrm{Y}=1.744 \\
\Sigma \mathrm{X}=925 & \Sigma \mathrm{XY}=54.417 \\
\Sigma \mathrm{X}^{2}=28.933 & \Sigma \mathrm{Y}^{2}=102.744
\end{array}
$$

Dimana a dan b dapat dicari melalui rumus : 


$$
a=\frac{\left(\sum y\right)\left(\sum x^{2}\right)-\left(\sum x\right)\left(\sum x y\right)}{n \sum x^{2}-\left(\sum x\right)^{2}} b=\frac{n \sum x y-\left(\sum x\right)\left(\sum y\right)}{n \sum x^{2}-\left(\sum x\right)^{2}}
$$

Setelah itu kemudian baru dilakukan perhitungan untuk mencari nilai a dan $\mathrm{b}$ dengan menggunakan rumus di atas :

$$
\begin{aligned}
a & =\frac{\left(\sum y\right)\left(\sum x^{2}\right)-\left(\sum x\right)\left(\sum x y\right)}{n \sum x^{2}-\left(\sum x\right)^{2}} \\
a & =\frac{(1.744)(28.933)-(925)(54.417)}{30 x 28.933-(925)^{2}} \\
a & =\frac{50.459 .152-50.335 .725}{867.990-855.625} \\
& =\frac{123.427}{12.365}=9,98 \\
b & =\frac{n \sum x y-\left(\sum x\right)\left(\sum y\right)}{n \sum x^{2}-\left(\sum x\right)^{2}} \\
b & =\frac{30 x 54.417-(925)(1.744)}{30 x 28.933-(925)^{2}} \\
b & =\frac{1.632 .510-1.613 .200}{867.990-855.625} \\
b & =\frac{19.310}{12.365}=1,56
\end{aligned}
$$

Dengan demikian persamaan regresinya :

$$
\begin{aligned}
& Y=a+b_{x} \\
& Y=9,98+1,56 X
\end{aligned}
$$

Persamaan ini mengandung makna bahwa apabila nilai $\mathrm{X}$ dinaikkan satu satuan maka nilai Y akan naik sebesar 1,56 pada tingkat konstanta 9,98.

\section{Penutup}

Pada rumusan masalah BAB I serta tabel hasil penelitian dan pembahasan pada BAB IV maka dapat disimpulkan sebagai berikut: Pelaksanaan pelayanan prima pada PT. BPR Surya Katialo. Hal ini dapat dilihat dari sejumlah pernyataan: Kemampuan/pengetahuan yang dimiliki karyawan PT. BPR Surya Katialo sudah memadai sehingga diharapkan dapat meningkatkan kepuasan nasabah. Sikap karyawan Bank dapat membuat nasabah merasa aman sehingga diharapkan meningkatkan kepuasan nasabah. Karyawan PT. BPR Surya Katialo berpenampilan rapi dan sopan setiap bekerja sehingga diharapkan dapat meningkatkan kepuasan nasabah. Karyawan selalu memberikan perhatian atas kebutuhan dan keperluan nasabah sehingga diharapkan dapat meningkatkan kepuasan nasabah. Karyawan selalu cepat dan tanggap dalam merespon keluhan nasabah sehingga diharapkan dapat meningkatkan kepuasan nasabah. Karyawan PT. BPR. Surya Katialo memberikan kemudahan prosedur pelayanan kepada nasabah sehingga diharapkan dapat meningkatkan kepuasan nasabah. Perkembangan kepuasan nasabah pada PT. BPR Surya Katialo. Hal ini dapat dilihat dari sejumlah pernyataan sebagai berikut: Kualitas pemasaran yang dilakukan PT. BPR Surya Katialo berupa relation marketing dapat meningkatkan kepuasan nasabah. Kualitas superior (customer service) yang dilakukan PT. BPR. Surya Katialo 
dapat meningkatkan kepuasan nasabah. Kualitas unconditional service guarantees yang dilakukan PT. BPR Surya Katialo dapat meningkatkan kepuasan nasabah. Kualitas penanganan keluhan yang efisien yang dilakukan PT. BPR. Surya Katialo dapat meningkatkan kepuasan nasabah. Kualitas peningkatan kinerja perusahaan yang dilakukan PT. BPR. Surya Katialo dapat meningkatkan kepuasan nasabah. Kualitas penerapan quality function deployment yang dilakukan PT. BPR. Surya Katialo dapat meningkatkan kepuasan nasabah. Pengaruh pelayanan prima terhadap peningkatan kepuasan nasabah PT. BPR Surya Katialo dapat dilihat melalui hasil uji statistik dibawah ini: Koefisien Korelasi (uji r) $=0,86$ / sangat kuat. Uji signifikasi (uji t) = $t_{\text {hitung }}>t_{\text {tabel }}$ atau 8,94 $>$ 2,052. Koefisien Determinasi $\left(u j i r^{2}\right.$ ) $=73,96 \%$ ini menunjukkan adanya pengaruh yang kuat yang ditimbulkan dari pelayanan prima untuk meningkatkan kepuasan nasabah. Sedangkan faktor lain yang mempengaruhi kepuasan nasabah adalah sebesar 100\% - 73,96\% $=26,04 \%$. Regresi Linear dihasilkan persamaan $\mathrm{Y}=9,98+1,56 \mathrm{X}$. Persamaan ini mengandung makna bahwa apabila nilai $\mathrm{X}$ dinaikkan satu satuan maka nilai $\mathrm{Y}$ akan naik sebesar 1,56 pada tingkat konstanta 9,98 .

\section{Daftar Pustaka}

Adya Brata, Atep. 2004. Dasar-Dasar Pelayanan Prima. Jakarta. Gramedia Pustaka Utama.

2006. Dasar-Dasar Pelayanan Prima Cetakan Ketiga. Jakarta. PT. Elex Media Komputindo.

Arikunto, Suharsimi. 2006. Prosedur Penelitian (Suatu Pendekatan Praktik). Jakarta. PT Rineka Cipta.

Hasibuan, Malayu. 2001. Manajemen Sumber Daya Manusia : Pengertian Dasar, Pengertian dan Masalah. Jakarta. PT. Toko Gunung Agung.

Keputusan Menteri Negara Pendayagunaan Aparatur Negara Nomor 81 Tahun 1993 Tentang Pedoman Tata Laksana Pelayanan Umum. Jakarta. Menpan.

Kotler, Philip. 2001. Manajemen Pemasaran: Analisis, Perencanaan, Implementasi, dan Kontrol. Jakarta. PT Prehallindo.

Kotler, Philip dan Gary Amstrong. 2012. Prinsip-Prinsip Pemasaran. Jakarta. Erlangga. Sudjana. 2000. Metoda Statistika. Bandung. Tarsito Bandung.

Sugiyono. 2002. Metode Penelitian. Bandung. Alphabeta. , 2004. Metode Penelitian Bisnis. Bandung. Alfabeta. 2007. Metode Penelitian Kuantitatif dan R \& D. Bandung. Alfabeta.

Sumarwan, Ujang. 2003. Perilaku Konsumen. Jakarta. Ghalia Indonesia. 